Supporting Information

\title{
Cathode-Supported All-Solid-State Lithium Sulfur Batteries with High Cell-Level Energy Density
}

Ruochen Xu ${ }^{\dagger, t}$ Jie Yue $e^{\dagger}$ Sufu Liu ${ }^{\dagger, t}$ Jiangping Tu $u^{\ddagger}$ Fudong Han ${ }^{*,}$ Ping Liu ${ }^{*}$, and Chunsheng Wang ${ }^{*}+$

$\dagger$ Department of Chemical and Biomolecular Engineering, University of Maryland, College Park, Maryland 20742, United States

$¥$ State Key Laboratory of Silicon Materials, Key Laboratory of Advanced Materials and Applications for Batteries of Zhejiang Province, and School of Materials Science\& Engineering, Zhejiang University, Hangzhou 310027, China

$\S$ Department of Nanoengineering, University of California, San Diego, La Jolla, California 92093, United States

\section{AUTHOR INFORMATION}

\section{Corresponding Author}

*Email: fdhan@umd.edu

*Email: piliu@eng.ucsd.edu

*Email: cswang@umd.edu 


\section{Experimental Methods}

Synthesis: $\mathrm{Li}_{3} \mathrm{PS}_{4}$ (LPS) glass solid electrolytes were prepared by a high-energy mechanical ball milling method. $\mathrm{Li}_{2} \mathrm{~S}$ (Sigma-Aldrich, 99.98\%) and $\mathrm{P}_{2} \mathrm{~S}_{5}$ (Sigma-Aldrich, 99\%) were used as starting materials $\left(75 \mathrm{~mol} \% \mathrm{Li}_{2} \mathrm{~S}, 25 \mathrm{~mol} \% \mathrm{P}_{2} \mathrm{~S}_{5}\right)$. The mixture of these materials was placed in a zirconia pot $(50 \mathrm{~mL})$ with ten zirconia balls $(10 \mathrm{~mm}$ in diameter) and ball-milled (PM 100, Retsch) at $510 \mathrm{rpm}$ for $40 \mathrm{~h}$ at room temperature. Anhydrous toluene (99.8\%, Sigma Aldrich) was used as the solvent after removal of water to disperse the LPS electrolytes for preparing ultra-thin sulfide solid electrolytes. The Kevlar nonwoven scaffold (ACP composites, thickness: $\sim 60 \mu \mathrm{m}$ ) was cut into pieces with $10 \mathrm{~mm}$ in diameter. Subsequently, the dried fiber pieces were placed into a $10 \mathrm{~mm}$ die and the LPS suspension was slowly added in the Kevlar nonwoven scaffold by a pipette (the amount of LPS suspension was controlled). The LPS-Kevlar electrolyte in the die was dried overnight in an argon-filled glove box and then cold-pressed together under $360 \mathrm{Mpa}$ (thickness: $\sim 100 \mu \mathrm{m}$, weight: $\sim 13.88 \mathrm{mg}$ ). For preparing the $\mathrm{Li}_{2} \mathrm{~S}-\mathrm{LiI}$ cathode, $\mathrm{Li}_{2} \mathrm{~S}$ (Sigma-Aldrich, 99.98\%) and LiI (Sigma-Aldrich, 99.999\%) powders was placed in a zirconia pot ( $\left.80 \mathrm{~mol} \% \mathrm{Li}_{2} \mathrm{~S}, 20 \mathrm{~mol} \% \mathrm{LiI}\right)$ and mechanically milled using a ball mill apparatus for $10 \mathrm{~h}$ at $510 \mathrm{rpm}$ at room temperature. The composite electrodes consisted of $\mathrm{Li}_{2} \mathrm{~S}-$ LiI active materials, vapor grown carbon fiber (VGCF) and LPS solid electrolyte in a weight ratio of 75: 10: 15 . The $\mathrm{Li}_{2} \mathrm{~S}-\mathrm{LiI}$ and carbon black was firstly mechanically milled at $510 \mathrm{rpm}$ for $10 \mathrm{~h}$, and then the $\mathrm{Li}_{2} \mathrm{~S}-\mathrm{LiI}-\mathrm{VGCF}$ powder and LPS electrolytes were softly milled at $150 \mathrm{rpm}$ for $0.5 \mathrm{~h}$. The obtained composite powders were mixed with polytetrafluoroethylene (PTFE) binder in a weight ratio of $85: 15$. The powders were then ground by hand in a mortar and rolled 
into a thin sheet using a metal rod, and then it was cut into pieces with $10 \mathrm{~mm}$ in diameter. The prepared composite electrodes $\left(\mathrm{Li}_{2} \mathrm{~S}-\mathrm{LiI}-\mathrm{VGCF}-\mathrm{LPS}\right)$ were directly used as working electrode $\left(\sim 6.89-20.71 \mathrm{mg} \mathrm{cm}^{-2}\right)$ and the loading of active material on the electrode is around 2.54-7.64 $\mathrm{mg} \mathrm{cm}^{-2}$. In addition, the stainless-steel mesh (SS, Sigma Aldrich, thickness: $\sim 60 \mu \mathrm{m}$ ) was cut into pieces (10 $\mathrm{mm}$ in diameter), and then the prepared $\mathrm{Li}_{2} \mathrm{~S}$ composite cathode piece and $\mathrm{SS}$ mesh pieces were cold-pressed together in a die under the pressure of $360 \mathrm{MPa}$.

Characterization: X-ray diffraction (XRD) measurements were performed for the prepared solid electrolytes using a D8 Advance with LynxEye and Solx (Bruker AXS, WI, USA) with Cu $\mathrm{K} \alpha$ line as radiation source. Raman spectra were measured on a Horiba Jobin Yvon Labram Aramis using a $532 \mathrm{~nm}$ diode-pumped solid-state laser. The morphologies of the samples were obtained using a Hitachi a SU-70 field-emission scanning electron microscope (SEM).

Electrochemistry: The ionic conductivities of LPS and LPS-Kevlar electrolyte were measured using electrochemical impedance spectroscopy (EIS) by blocking symmetric cells. The assynthesized LPS powder (150 mg) was cold-pressed under $360 \mathrm{MPa}$ with the thickness of around $1 \mathrm{~mm}$ in a Swagelok Cell (10 $\mathrm{mm}$ in diameter). The LPS-Kevlar electrolyte was also placed in a Swagelok Cell. Pt was sputtering on both sides of the pellets to prepare the Pt/LPS/Pt and Pt/LPS-Kevlar/Pt cells. The non-blocking symmetric Li/LPS/Li and Li/LPS-Kevlar/Li cells were assembled by pressing two lithium foils on both sides of the pellets in an argon-filled glove box. All-solid-state lithium cells were fabricated by employing $\mathrm{Li}_{2} \mathrm{~S}-\mathrm{Li}$-VGCF-LPS-SS 
composite as cathode, LPS-Kevlar as solid electrolyte and Li metal as anode. For the assembly of the all-solid-state cells, the cathode piece was firstly put in a die. Subsequently, the dried fiber pieces were placed on the cathode piece and the LPS suspension was slowly added in the fiber piece by a pipette (the amount of LPS suspension was controlled). The composite cathode and LPS-Kevlar electrolyte in the die were dried overnight and then cold-pressed together under 360 Mpa. After that, a $45 \mu \mathrm{m}$ thick Li foil was attached to the other side of the solid electrolyte as a counter and reference electrode. Finally, the three-layered pellet was attached with two stainless steel disks as current collectors. All the preparation processes were performed in a dry argonfilled glovebox $\left(\mathrm{O}_{2}<0.1 \mathrm{ppm}, \mathrm{H}_{2} \mathrm{O}<0.1 \mathrm{ppm}\right)$. The EIS measurements were carried out at frequencies from $1 \mathrm{MHz}$ to $0.1 \mathrm{~Hz}$ with the $\mathrm{AC}$ amplitude of $20 \mathrm{mV}$ by an electrochemistry workstation (Solatron 1287/1260). The galvanostatic discharge-charge cycles were tested using an Arbin BT2000 workstation (Arbin Instruments, TX, USA) in a voltage of $1.2-3.0 \mathrm{~V}$ at room temperature. The currents and specific capacities were calculated on the basis of the weight of $\mathrm{Li}_{2} \mathrm{~S}$ in the cathode. 


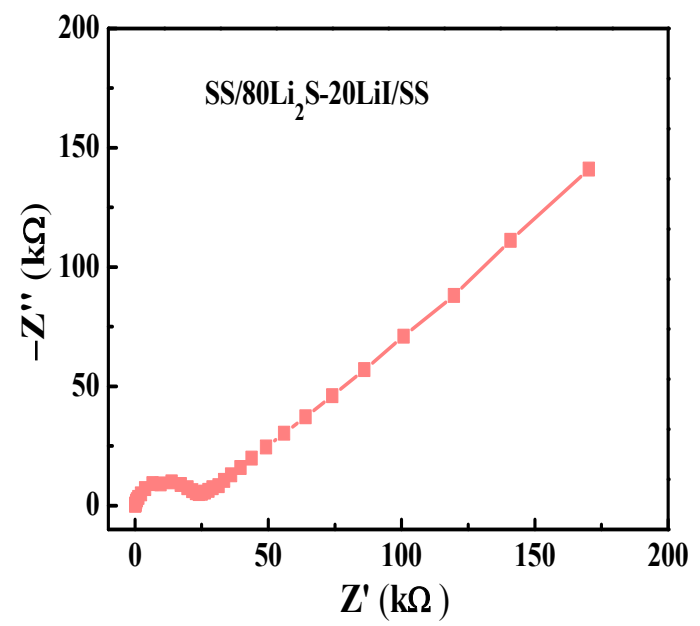

Figure S1. Impedance plot of the $\mathrm{SS} / 80 \mathrm{Li}_{2} \mathrm{~S}-20 \mathrm{LiI} / \mathrm{SS}$ cell. The ionic conductivity of $80 \mathrm{Li}_{2} \mathrm{~S}-20 \mathrm{LiI}$ at room temperature is calculated to be $2.6 \times 10^{-6} \mathrm{~S} \mathrm{~cm}^{-1}$. 


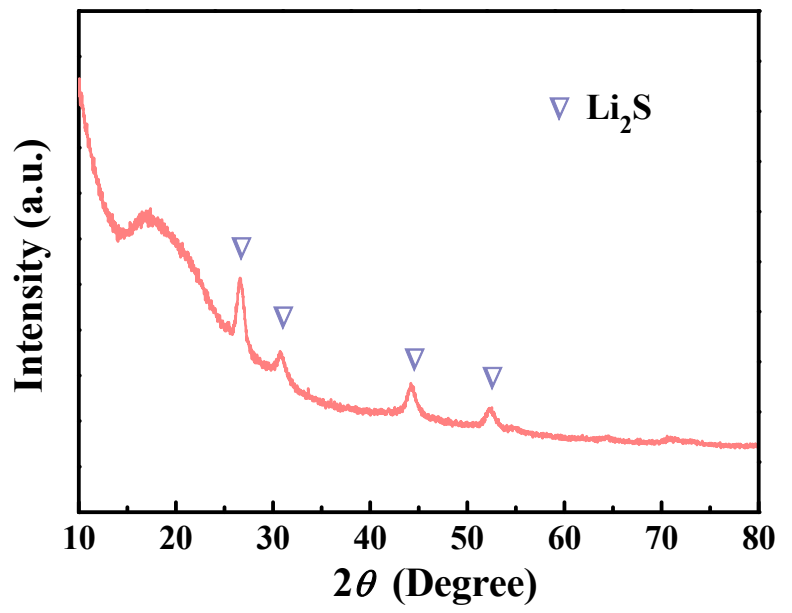

Figure S2. X-ray diffraction pattern of the cathode composite. 

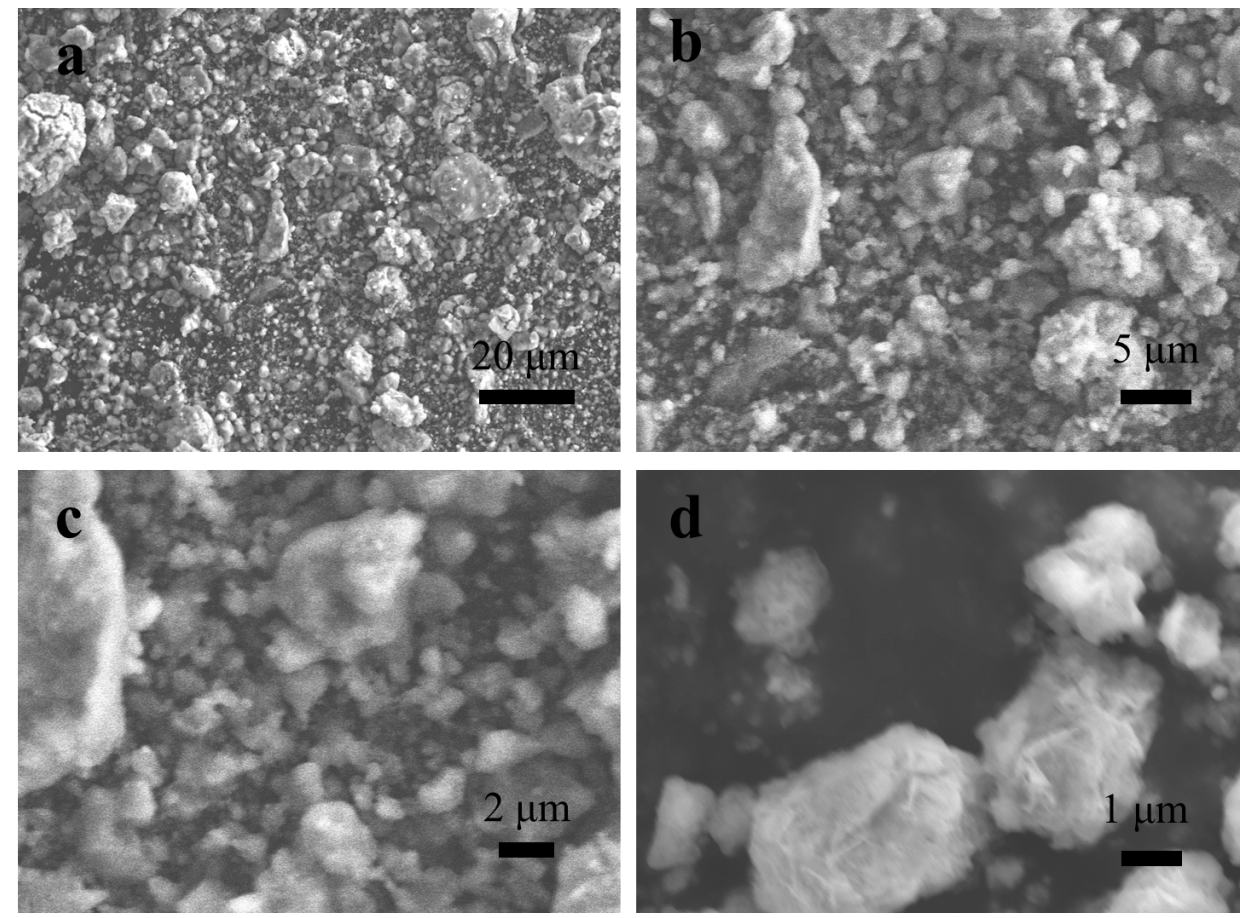

Figure S3. (a-d) SEM images of the cathode composite at different magnifications. The magnification increases from (a) to (d). 

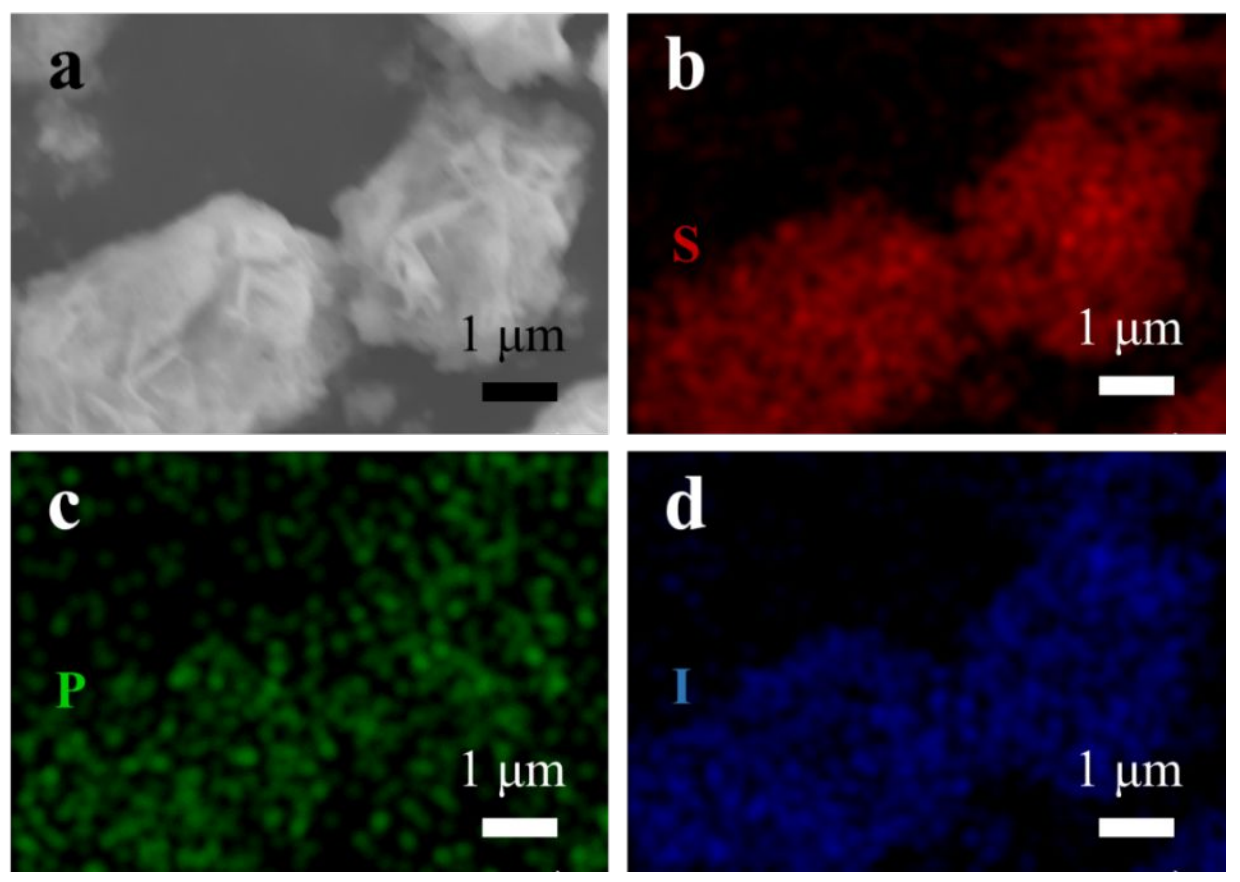

Figure S4. SEM image (a) and elemental mappings of S (b), P (c) and I (d) in the cathode composite. 

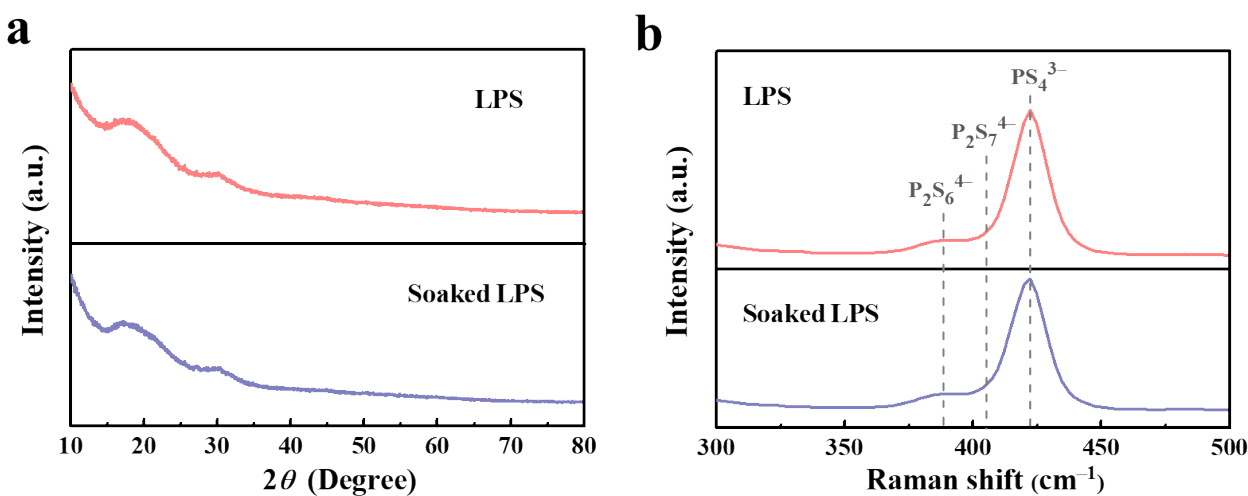

Figure S5. (a) XRD patterns and (b) Raman spectra of the as-prepared LPS and LPS dried from the LPS suspension in toluene. 

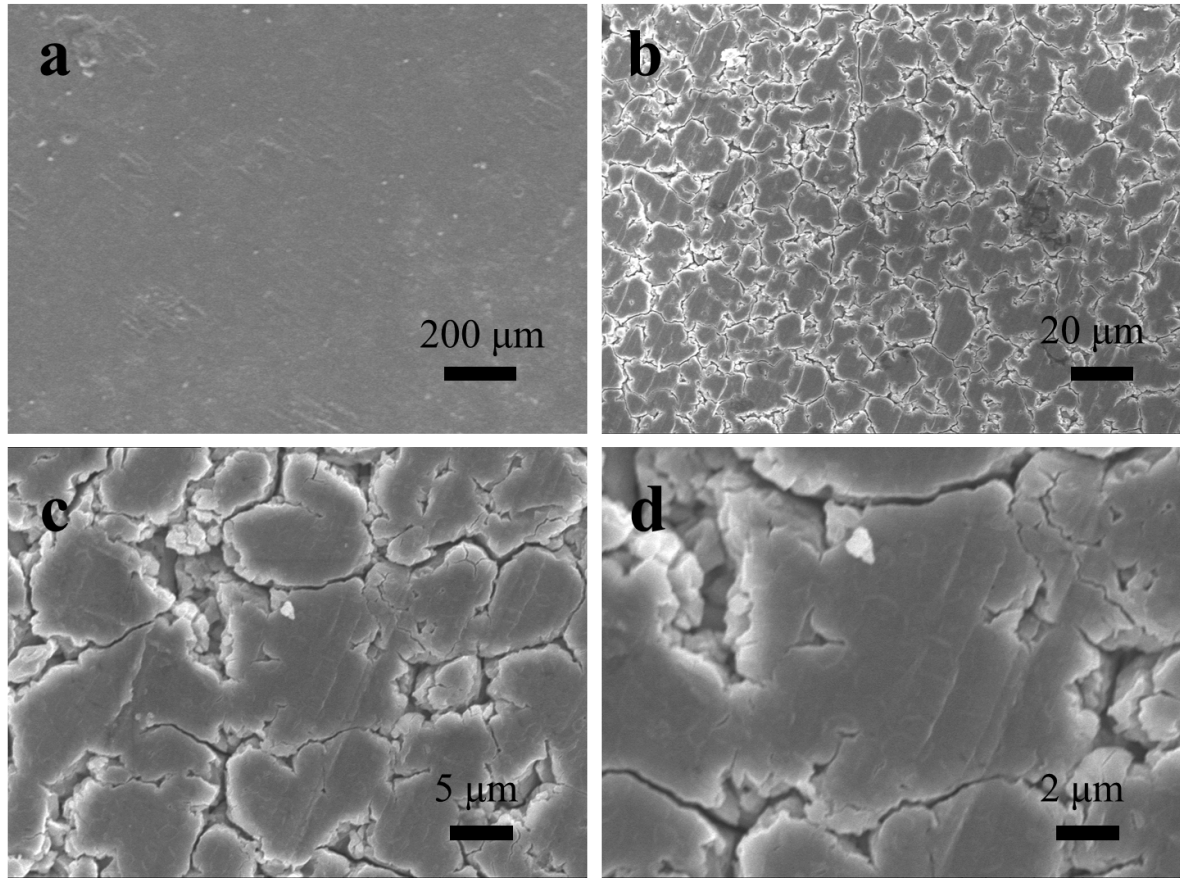

Figure S6. (a-d) SEM images of the surface of cold-pressed LPS-Kevlar electrolyte at different magnifications. The magnification increases from (a) to (d). 

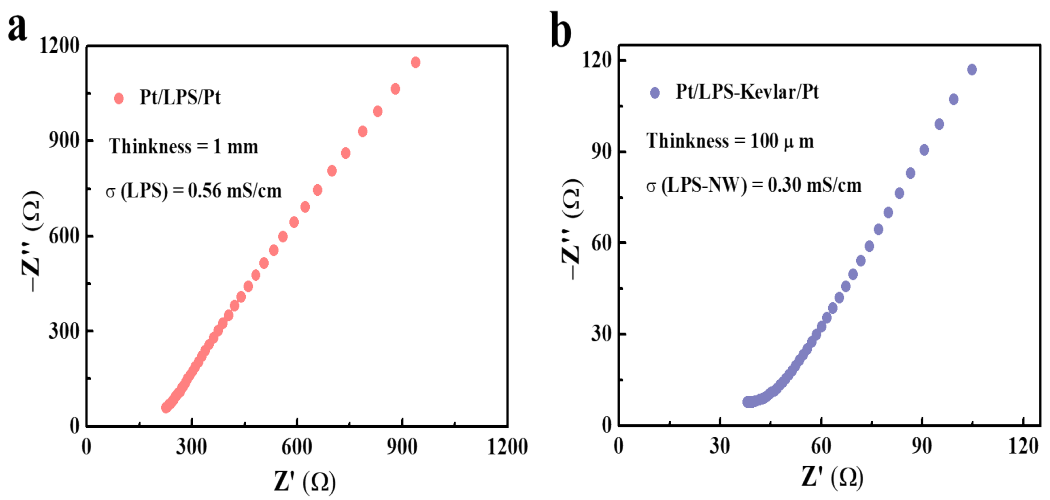

Figure S7. Nyquist plots of the (a) Pt/LPS/Pt and (b) Pt/LPS-Kevlar/Pt blocking cells at $25^{\circ} \mathrm{C}$. 


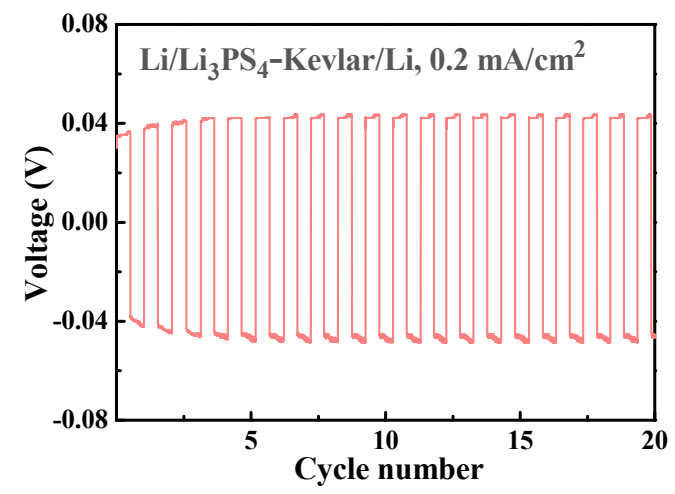

Figure S8. Galvanostatic cycling of the Li/LPS-Kevlar/Li cell at $0.2 \mathrm{~mA} \mathrm{~cm}{ }^{-2}$ at $25^{\circ} \mathrm{C}$. The time for each charge and discharge is 30 minutes. 

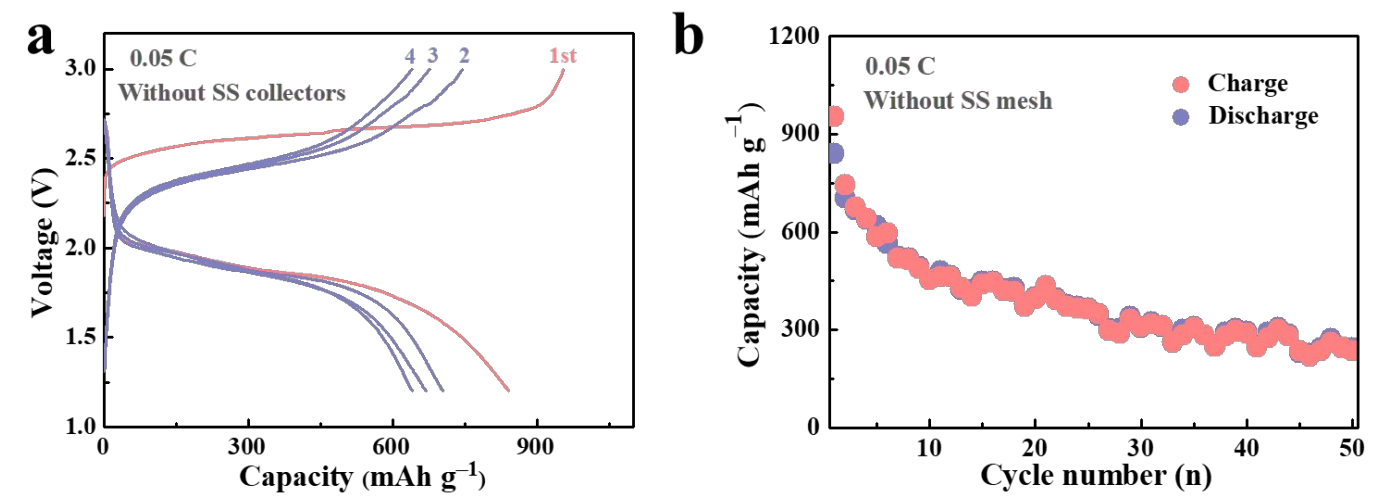

Figure S9. (a) Charge-discharge profiles and (b) cycle performance of all-solid-state $\mathrm{Li}-\mathrm{Li}_{2} \mathrm{~S}$ cell without SS mesh current collector. 


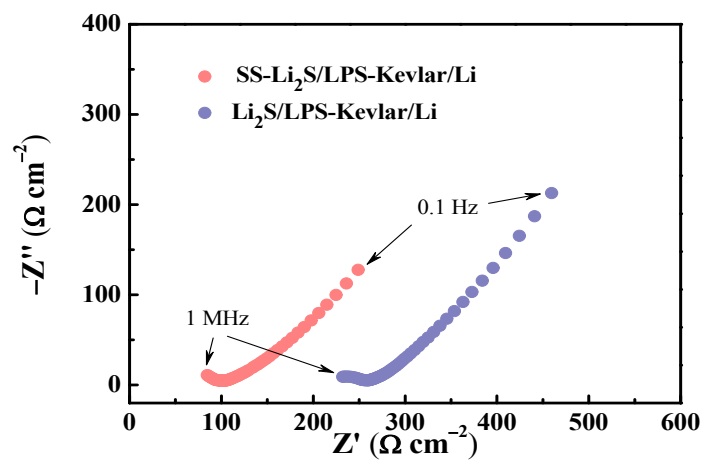

Figure S10. Nyquist plots of all-solid-state $\mathrm{Li}-\mathrm{Li}_{2} \mathrm{~S}$ cells with (red) and without (blue) SS mesh current collector. The EIS was tested at the fully discharged state of the cells after 50 cycles. 

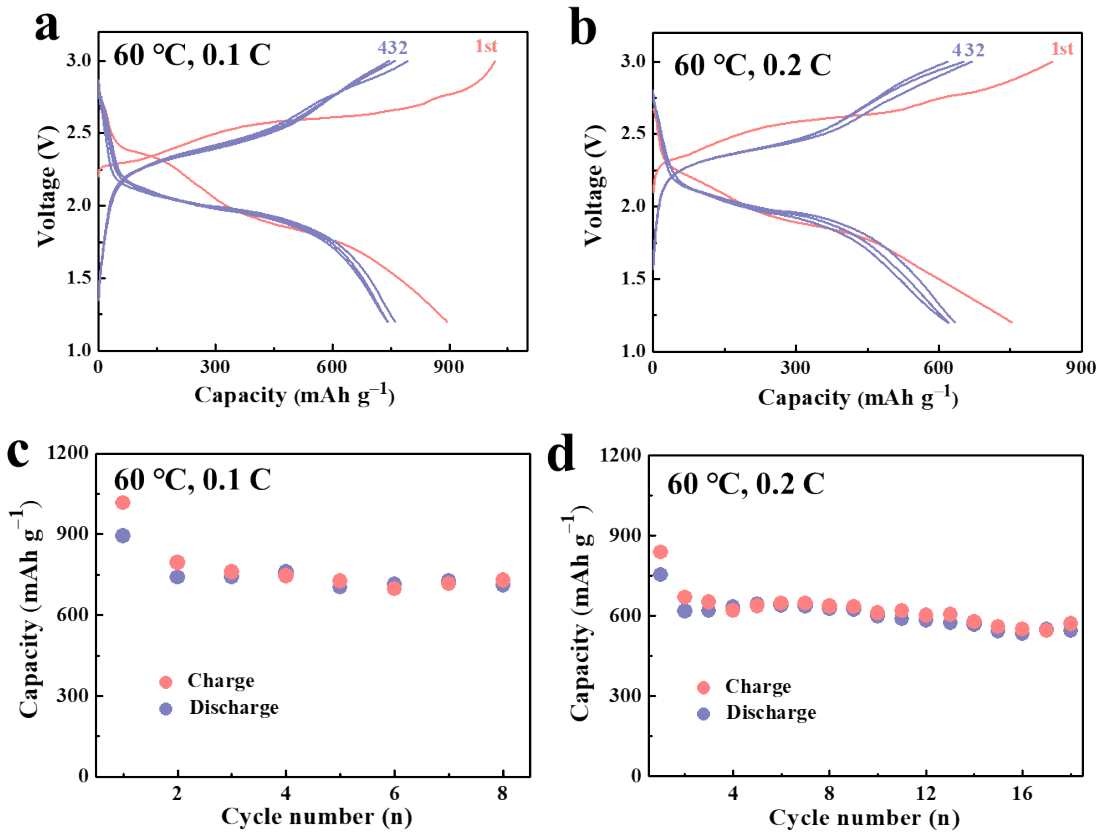

Figure S11. Charge-discharge profiles of the cathode-supported all-solid-state $\mathrm{Li}-\mathrm{Li}_{2} \mathrm{~S}$ cells at (a) $0.1 \mathrm{C}$ and (b) $0.2 \mathrm{C}$ at $60{ }^{\circ} \mathrm{C}$. Cycling performance of the cathode-supported all-solid-state $\mathrm{Li}-\mathrm{Li}_{2} \mathrm{~S}$ cells at (c) $0.1 \mathrm{C}$ and (d) $0.2 \mathrm{C}$ at $60^{\circ} \mathrm{C}$. 
$\mathbf{a}$

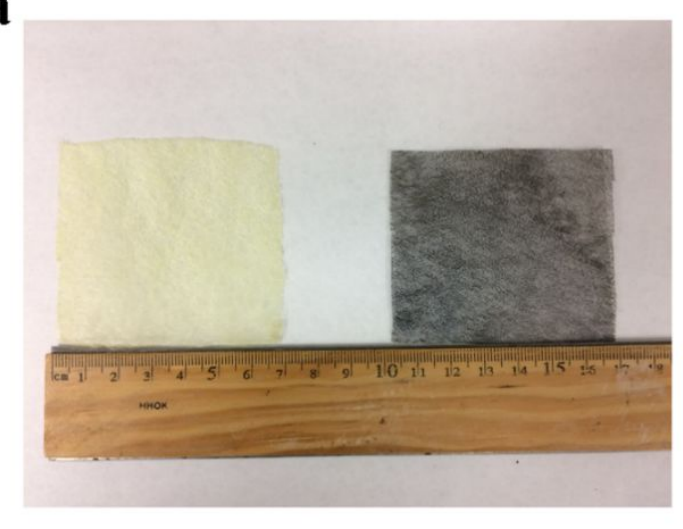

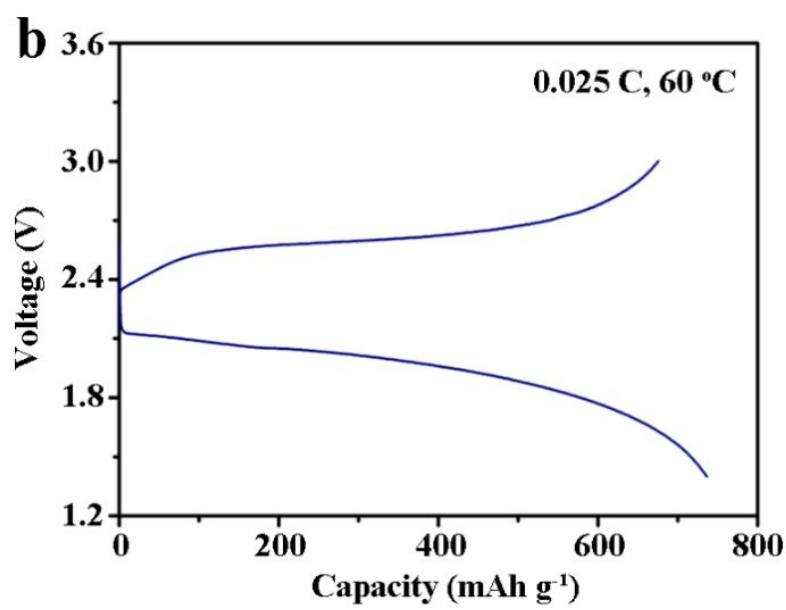

Figure 12. (a) Photo of the Kevlar nonwoven with and without Ni coating. $100 \mathrm{~nm}$ thick Ni was coated on both sides of the Kevlar nonwoven. (b) Charge-discharge of the cathode-supported all-solid-state Li$\mathrm{Li}_{2} \mathrm{~S}$ cell with Ni coated Kevlar nonwoven as the current collector for the cathode. The weight of the SS mesh and Ni coated Kevlar nonwoven is 53.3 and $1.2 \mathrm{mg} \mathrm{cm}^{-2}$, respectively. 
Table S1. Cell-level energy densities of all-solid-state cells using sulfides as the electrolyte. The tables are classified based on the type of cathode used in the cell.

\section{LCO cell:}

\begin{tabular}{|c|c|c|c|c|c|c|c|c|c|}
\hline Cathode & Electrolyte & Anode & $\begin{array}{c}\text { Weight of } \\
\text { cathode } \\
\text { (loading) } \\
\text { (mg) }\end{array}$ & $\begin{array}{c}\text { Weight } \\
\text { of SE } \\
\text { (mg) }\end{array}$ & $\begin{array}{c}\text { Weight } \\
\text { of } \\
\text { anode } \\
\text { (mg) }\end{array}$ & $\begin{array}{l}\text { Capacity } \\
\left(\mathrm{mAh} \mathrm{g}^{-1}\right)\end{array}$ & $\begin{array}{c}\text { Average } \\
\text { voltage } \\
\text { (V) }\end{array}$ & $\begin{array}{c}\text { Energy } \\
\text { density } \\
(W h \\
\left.\mathbf{k g}^{-1}\right)\end{array}$ & Ref. \\
\hline $\mathrm{LiCoO}_{2}$ & $\begin{array}{l}77.5 \mathrm{Li}_{2} \mathrm{~S} \cdot 22.5 \mathrm{P}_{2} \mathrm{~S}_{5} \\
/ 67.5 \mathrm{Li}_{2} \mathrm{~S} \cdot 25 \mathrm{P}_{2} \mathrm{~S}_{5} \\
7.5 \mathrm{Li}_{2} \mathrm{O}\end{array}$ & $\mathrm{Li}$ & $10(3.77)$ & 200 & 50.7 & 90 & 3.7 & 4.8 & 1 \\
\hline $\mathrm{LiCoO}_{2}$ & $\begin{array}{l}\mathrm{Li}_{3.15} \mathrm{Ge}_{0.15} \mathrm{P}_{0.85} \mathrm{~S}_{4} / \\
77.5 \mathrm{Li}_{2} \mathrm{~S} \cdot 22.5 \mathrm{P}_{2} \mathrm{~S}_{5}\end{array}$ & $\mathrm{Li}$ & $10(3.77)$ & 200 & 50.7 & 130 & 3.7 & 7.0 & 2 \\
\hline $\mathrm{LiCoO}_{2}$ & $78 \mathrm{Li}_{2} \mathrm{~S} \cdot 22 \mathrm{P}_{2} \mathrm{~S}_{5}$ & In & $25(9.75)$ & 140 & 146.9 & 110 & 3.1 & 10.7 & 3 \\
\hline $\mathrm{LiCoO}_{2}$ & $78 \mathrm{Li}_{2} \mathrm{~S} \cdot 22 \mathrm{P}_{2} \mathrm{~S}_{5}$ & In & $25(9.75)$ & 140 & 146.9 & 112 & 3.1 & 10.9 & 4 \\
\hline $\mathrm{LiCoO}_{2}$ & $\mathrm{Li}_{3} \mathrm{PS}_{4}$ & In & $5(3.5)$ & 80 & 57.4 & 150 & 3.1 & 11.4 & 5 \\
\hline $\mathrm{LiCoO}_{2}$ & $\begin{array}{l}\mathrm{Li}_{2} \mathrm{~S} \cdot \mathrm{GeS}_{2} \cdot \mathrm{P}_{2} \mathrm{~S}_{5} / 7 \\
7.5 \mathrm{Li}_{2} \mathrm{~S} \cdot 22.5 \mathrm{P}_{2} \mathrm{~S}_{5}\end{array}$ & $\mathrm{Li}$ & $10(3.77)$ & 200 & 50 & 220 & 3.7 & 11.8 & 6 \\
\hline $\mathrm{LiCoO}_{2}$ & $78 \mathrm{Li}_{2} \mathrm{~S} \cdot 22 \mathrm{P}_{2} \mathrm{~S}_{5}$ & In & $25(9.75)$ & 140 & 146.9 & 127.2 & 3.1 & 12.3 & 7 \\
\hline $\mathrm{LiCoO}_{2}$ & $\mathrm{Li}_{3.25} \mathrm{Ge}_{0.25} \mathrm{P}_{0.75} \mathrm{~S}_{4}$ & Li-In & $\begin{array}{r}12.7 \\
(8.89) \\
\end{array}$ & 150 & 60 & 115 & 3.1 & 14.2 & 8 \\
\hline $\mathrm{LiCoO}_{2}$ & $\mathrm{Li}_{10} \mathrm{GeP}_{2} \mathrm{~S}_{12}$ & Graphite & $10(7)$ & 80 & 20 & 104 & 2.2 & 14.6 & 9 \\
\hline $\mathrm{LiCoO} 2$ & $\mathrm{Li}_{3.25} \mathrm{Ge}_{0.25} \mathrm{P}_{0.75} \mathrm{~S}_{4}$ & Li-In & $\begin{array}{r}12.7 \\
(8.89) \\
\end{array}$ & 150 & 60 & 120 & 3.1 & 14.8 & 10 \\
\hline $\mathrm{LiCoO}_{2}$ & $80 \mathrm{Li}_{2} \mathrm{~S} \cdot 20 \mathrm{P}_{2} \mathrm{~S}_{5}$ & In & $10(7)$ & 80 & 57.4 & 105 & 3.1 & 15.5 & 11 \\
\hline $\mathrm{LiCoO}_{2}$ & $80 \mathrm{Li}_{2} \mathrm{~S} \cdot 20 \mathrm{P}_{2} \mathrm{~S}_{5}$ & In & $10(7)$ & 80 & 57.4 & 105 & 3.1 & 15.5 & 12 \\
\hline $\mathrm{LiCoO}_{2}$ & $\mathrm{Li}_{10} \mathrm{GeP}_{2} \mathrm{~S}_{12}$ & Li-In & $10(7)$ & 100 & 58.4 & 124 & 3.1 & 16.0 & 13 \\
\hline $\mathrm{LiCoO}_{2}$ & $78 \mathrm{Li}_{2} \mathrm{~S} \cdot 22 \mathrm{P}_{2} \mathrm{~S}_{5}$ & In & $15(12)$ & 150 & 146.9 & 145 & 3.1 & 17.3 & 14 \\
\hline $\mathrm{LiCoO}_{2}$ & $\begin{array}{l}96\left(78 \mathrm{Li}_{2} \mathrm{~S} \cdot 22 \mathrm{P}_{2} \mathrm{~S}_{5}\right. \\
) \cdot 4 \mathrm{Li}_{2} \mathrm{SO}_{4}\end{array}$ & In & $20(14)$ & 200 & 146.9 & 150.5 & 3.1 & 17.8 & 15 \\
\hline $\mathrm{LiCoO}_{2}$ & $\mathrm{Li}_{10} \mathrm{GeP}_{2} \mathrm{~S}_{12}$ & In & $10(7)$ & 80 & 45.9 & 120 & 3.1 & 19.2 & 9 \\
\hline $\mathrm{LiCoO}_{2}$ & $\mathrm{Li}_{10} \mathrm{GeP}_{2} \mathrm{~S}_{12}$ & In & $10(7)$ & 80 & 45.9 & 122 & 3.1 & 19.5 & 16 \\
\hline $\mathrm{LiCoO}_{2}$ & $\mathrm{Li}_{4} \mathrm{SnS}_{4}$ & Li-In & $15(12.75)$ & 150 & 100 & 140 & 3.1 & 20.9 & 17 \\
\hline $\mathrm{LiCoO}_{2}$ & $\mathrm{Li}_{10} \mathrm{GeP}_{2} \mathrm{~S}_{12}$ & In & $10(8)$ & 80 & 45.9 & 134 & 3.1 & 24.5 & 18 \\
\hline $\mathrm{LiCoO}_{2}$ & $\begin{array}{l}97\left(0.78 \mathrm{Li}_{2} \mathrm{~S} \cdot 0.22\right. \\
\left.\mathrm{P}_{2} \mathrm{~S}_{5}\right) \cdot 3 \mathrm{Li}_{3} \mathrm{BO}_{3}\end{array}$ & Li-In & 15 (11.76) & 150 & 30 & 156 & 3.7 & 34.8 & 19 \\
\hline $\mathrm{LiCoO}_{2}$ & $\begin{array}{l}0.01 \mathrm{Li}_{3} \mathrm{PO}_{4} \cdot 0.63 \mathrm{~L} \\
\mathrm{i}_{2} \mathrm{~S} \cdot 0.36 \mathrm{SiS}_{2}\end{array}$ & In & $20(14)$ & 55 & 57.4 & 113.3 & 3.1 & 37.1 & 20 \\
\hline $\mathrm{LiCoO}_{2}$ & $\begin{array}{l}\mathrm{LiI} \cdot \mathrm{Li}_{2} \mathrm{~S} \cdot \mathrm{P}_{2} \mathrm{~S}_{5} / \mathrm{Li}_{2} \\
\mathrm{~S} \cdot \mathrm{GeS}_{2} \cdot \mathrm{P}_{2} \mathrm{~S}_{5}\end{array}$ & Graphite & $15(-)$ & 150 & 37 & - & 3.7 & 43.0 & 21 \\
\hline
\end{tabular}




\begin{tabular}{|l|l|c|c|c|c|c|c|c|c|}
\hline $\mathrm{LiCoO}_{2}$ & $\mathrm{Li}_{3} \mathrm{PS}_{4}$ & $\begin{array}{c}\mathrm{Li}_{4} \mathrm{Ti}_{5} \mathrm{O}_{1} \\
2\end{array}$ & - & - & - & - & - & 44.0 & 22 \\
\hline $\mathrm{LiCoO}_{2}$ & $\begin{array}{l}7 \mathrm{Li}_{2} \mathrm{O} \cdot 68 \mathrm{Li}_{2} \mathrm{~S} \cdot 25 \mathrm{P} \\
{ }_{2} \mathrm{~S}_{5}\end{array}$ & Graphite & $\begin{array}{c}16.2 \\
(11.3)\end{array}$ & 65 & 12 & 107 & 3.7 & 48.0 & 23 \\
\hline $\mathrm{LiCoO}_{2}$ & $\mathrm{Li}_{3} \mathrm{PS}_{4}$ & Graphite & $\begin{array}{c}16.2 \\
(11.3)\end{array}$ & 65 & 12 & 108 & 3.7 & 48.6 & 24 \\
\hline $\mathrm{LiCoO}_{2}$ & $\begin{array}{l}\mathrm{Li}_{10} \mathrm{GeP}_{2} \mathrm{~S}_{12} / \mathrm{Li}_{9.6} \mathrm{P} \\
{ }_{2} \mathrm{~S}_{12}\end{array}$ & Graphite & - & - & - & - & - & 133.0 & 25 \\
\hline $\mathrm{LiCoO}_{2}$ & $\begin{array}{l}30 \mathrm{LiI}^{2} \cdot 70\left(0.75 \mathrm{Li}_{2} \mathrm{~S}\right. \\
\left.-0.25 \mathrm{P}_{2} \mathrm{~S}_{5}\right)\end{array}$ & Graphite & - & - & - & - & - & 180.0 & 26 \\
\hline
\end{tabular}

\section{$\mathrm{Li}[\mathrm{Ni}, \mathrm{Co}, \mathrm{Mn}] \mathrm{O}_{2}$ cells:}

\begin{tabular}{|c|c|c|c|c|c|c|c|c|c|}
\hline Cathode & Electrolyte & Anode & $\begin{array}{l}\text { Weight of } \\
\text { cathode } \\
\text { (loading) } \\
\text { (mg) }\end{array}$ & $\begin{array}{c}\text { Weight } \\
\text { of SE } \\
\text { (mg) }\end{array}$ & $\begin{array}{c}\text { Weight } \\
\text { of } \\
\text { anode } \\
\text { (mg) }\end{array}$ & $\begin{array}{l}\text { Capacity } \\
\left(\mathbf{m A h ~} \mathrm{g}^{-1}\right)\end{array}$ & $\begin{array}{c}\text { Average } \\
\text { voltage } \\
\text { (V) }\end{array}$ & $\begin{array}{c}\text { Energy } \\
\text { density } \\
(W h \\
\left.\mathbf{k g}^{-1}\right)\end{array}$ & Ref. \\
\hline $\begin{array}{l}\mathrm{LiNi}_{1 / 3} \mathrm{Co}_{1} \\
{ }_{/ 3} \mathrm{Mn}_{1 / 3} \mathrm{O}_{2}\end{array}$ & $\begin{array}{l}80 \mathrm{Li}_{2} \mathrm{~S} \cdot 19 \mathrm{P}_{2} \mathrm{~S}_{5} \cdot 1 \mathrm{P} \\
{ }_{2} \mathrm{O}_{5}\end{array}$ & In & $10(3.85)$ & 80 & 57.4 & 115 & 3.1 & 9.3 & 27 \\
\hline $\begin{array}{l}\mathrm{LiNi}_{1 / 3} \mathrm{Co}_{1} \\
{ }_{3} \mathrm{Mn}_{1 / 3} \mathrm{O}_{2}\end{array}$ & $\mathrm{Li}_{6} \mathrm{PS}_{5} \mathrm{Cl}$ & In & $10(8.4)$ & 80 & 40 & 44 & 3.3 & 9.4 & 28 \\
\hline $\begin{array}{l}\mathrm{LiNi}_{1 / 3} \mathrm{Co}_{1} \\
{ }_{13} \mathrm{Mn}_{1 / 3} \mathrm{O}_{2}\end{array}$ & $\mathrm{Li}_{6} \mathrm{PS}_{5} \mathrm{Br}$ & In & $10(8.4)$ & 80 & 57.4 & 109 & 3.3 & 20.5 & 29 \\
\hline $\begin{array}{l}\mathrm{LiNi}_{1 / 3} \mathrm{Co}_{1} \\
{ }_{/ 3} \mathrm{Mn}_{1 / 3} \mathrm{O}_{2} \\
\end{array}$ & $75 \mathrm{Li}_{2} \mathrm{~S} \cdot 25 \mathrm{P}_{2} \mathrm{~S}_{5}$ & Li-In & $10(7.5)$ & 80.8 & 46.5 & 150 & 3.3 & 27.0 & 30 \\
\hline $\begin{array}{l}\mathrm{LiNi}_{1 / 3} \mathrm{Co}_{1} \\
{ }_{/ 3} \mathrm{Mn}_{1 / 3} \mathrm{O}_{2} \\
\end{array}$ & $75 \mathrm{Li}_{2} \mathrm{~S} \cdot 25 \mathrm{P}_{2} \mathrm{~S}_{5}$ & graphite & - & - & - & - & - & 155.0 & 31 \\
\hline $\begin{array}{l}\mathrm{LiNi}_{0.8} \mathrm{Co}_{0} \\
{ }_{.1} \mathrm{Mn}_{0.1} \mathrm{O}_{2}\end{array}$ & $\mathrm{Li}_{3} \mathrm{PS}_{4}$ & In & $12(8.4)$ & 60 & 71.75 & 124 & 3.1 & 22.5 & 32 \\
\hline $\begin{array}{l}\mathrm{LiNi}_{0.8} \mathrm{Co}_{0} \\
{ }_{15} \mathrm{Al}_{0.05} \mathrm{O}_{2} \\
\end{array}$ & $80 \mathrm{Li}_{2} \mathrm{~S} \cdot 20 \mathrm{P}_{2} \mathrm{~S}_{5}$ & Graphite & $15(9)$ & 70 & 15 & 120 & 3.7 & 40.0 & 33 \\
\hline $\begin{array}{l}\mathrm{LiNi}_{0.6} \mathrm{Co}_{0} \\
{ }_{2} \mathrm{Mn}_{0.2} \mathrm{O}_{2} \\
\end{array}$ & $\mathrm{Li}_{6} \mathrm{PS}_{5} \mathrm{Cl}$ & graphite & - & - & - & - & - & 184.0 & 34 \\
\hline $\begin{array}{l}\mathrm{LiNi}_{0.5} \mathrm{Mn} \\
{ }_{0.5} \mathrm{O}_{2}\end{array}$ & $\begin{array}{l}95\left(0.6 \mathrm{Li}_{2} \mathrm{~S} \cdot 0.4 \mathrm{SiS}\right. \\
\left.{ }_{2}\right) \cdot 5 \mathrm{Li}_{4} \mathrm{SiO}_{4}\end{array}$ & In & $20(7.55)$ & 80 & 57.4 & 70 & 3.1 & 10.4 & 35 \\
\hline $\mathrm{LiMn}_{2} \mathrm{O}_{4}$ & $80 \mathrm{Li}_{2} \mathrm{~S} \cdot 20 \mathrm{P}_{2} \mathrm{~S}_{5}$ & In & $10(3.85)$ & 80 & 57.4 & 55 & 3.5 & 5.0 & 36 \\
\hline $\mathrm{LiMn}_{2} \mathrm{O}_{4}$ & $80 \mathrm{Li}_{2} \mathrm{~S} \cdot 20 \mathrm{P}_{2} \mathrm{~S}_{5}$ & In & $10(3.85)$ & 80 & 57.4 & 72 & 3.5 & 6.6 & 37 \\
\hline $\begin{array}{l}\mathrm{LiAl}_{0.08} \mathrm{Co} \\
0.92 \mathrm{O}_{2}\end{array}$ & $\mathrm{Li}_{3.25} \mathrm{Ge}_{0.25} \mathrm{P}_{0.75} \mathrm{~S}_{4}$ & Li-In & $10(7)$ & 150 & 60 & 140 & 3.3 & 14.7 & 38 \\
\hline
\end{tabular}


$\mathbf{M}_{x} S$ cells:

\begin{tabular}{|c|c|c|c|c|c|c|c|c|c|}
\hline Cathode & Electrolyte & Anode & $\begin{array}{l}\text { Weight of } \\
\text { cathode } \\
\text { (loading) } \\
\text { (mg) }\end{array}$ & $\begin{array}{l}\text { Weight } \\
\text { of SE } \\
\text { (mg) }\end{array}$ & $\begin{array}{c}\text { Weight } \\
\text { of } \\
\text { anode } \\
\text { (mg) }\end{array}$ & $\begin{array}{l}\text { Capacity } \\
\left(\mathbf{m A h} \mathrm{g}^{-1}\right)\end{array}$ & $\begin{array}{c}\text { Average } \\
\text { voltage } \\
\text { (V) }\end{array}$ & $\begin{array}{c}\text { Energy } \\
\text { density } \\
(\mathrm{Wh} \\
\left.\mathrm{kg}^{-1}\right)\end{array}$ & Ref. \\
\hline $\mathrm{Co}_{9} \mathrm{~S}_{8}$ & $\begin{array}{l}\mathrm{Li}_{10} \mathrm{GeP}_{2} \mathrm{~S}_{12} / 70 \mathrm{Li}_{2} \\
\mathrm{~S} \cdot 29 \mathrm{P}_{2} \mathrm{~S}_{5} \cdot 1 \mathrm{P}_{2} \mathrm{O}_{5}\end{array}$ & $\mathrm{Li}$ & $2.75(1.0)$ & 150 & 4.19 & 633 & 2.28 & 9.2 & 39 \\
\hline $\mathrm{FeS}_{2}$ & $\mathrm{Na}_{3} \mathrm{PS}_{4} / \mathrm{Na}_{3} \mathrm{SbS}_{4}$ & $\mathrm{Na}_{3} \mathrm{Sn}$ & $5(4.35)$ & 120 & 50 & 346 & 1.68 & 14.4 & 40 \\
\hline $\mathrm{LiTi}_{2}\left(\mathrm{PS}_{4}\right)$ & $75 \mathrm{Li}_{2} \mathrm{~S} \cdot 25 \mathrm{P}_{2} \mathrm{~S}_{5}$ & Li-In & $5(3.5)$ & 200 & 100 & 1040 & 1.68 & 20.0 & 41 \\
\hline $\mathrm{Na}_{2} \mathrm{~S}$ & $\mathrm{Na}_{3} \mathrm{PS}_{4}$ & $\mathrm{Na}-\mathrm{Sn}-\mathrm{C}$ & $5(1.25)$ & 120 & 100 & 869.2 & 1.68 & 8.1 & 42 \\
\hline $\mathrm{Na}_{2} \mathrm{~S}$ & $\mathrm{Na}_{3} \mathrm{PS}_{4}$ & $\mathrm{Na}-\mathrm{Sn}-\mathrm{C}$ & $5(1.5)$ & 120 & 100 & 1050 & 1.68 & 11.8 & 43 \\
\hline $\mathrm{NiS}$ & $\begin{array}{l}\mathrm{Li}_{10} \mathrm{GeP}_{2} \mathrm{~S}_{12} / 70 \mathrm{Li}_{2} \\
\mathrm{~S} \cdot 29 \mathrm{P}_{2} \mathrm{~S}_{5} \cdot 1 \mathrm{P}_{2} \mathrm{O}_{5}\end{array}$ & $\mathrm{Li}$ & $10(4.5)$ & 150 & 4.19 & 670 & 2.28 & 41.9 & 44 \\
\hline $\mathrm{TiS}_{2}$ & $77.5 \mathrm{Li}_{2} \mathrm{~S} \cdot 22.5 \mathrm{P}_{2} \mathrm{~S}_{5}$ & $\mathrm{Li}$ & $10(3.2)$ & 200 & 50.7 & 208 & 2.28 & 5.8 & 45 \\
\hline $\mathrm{TiS}_{2}$ & $\mathrm{Li}_{10} \mathrm{GeP}_{2} \mathrm{~S}_{12}$ & Li-In & $10(4.87)$ & 150 & 100 & 289 & 1.68 & 9.1 & 46 \\
\hline $\mathrm{TiS}_{2}$ & $\begin{array}{l}\mathrm{Li}_{3} \mathrm{PS}_{4} / \mathrm{Li}_{10} \mathrm{GeP}_{2} \mathrm{~S}_{1} \\
2\end{array}$ & Li-In & $10(5)$ & 150 & 50 & 239 & 1.68 & 9.6 & 47 \\
\hline $\mathrm{TiS}_{2}$ & $\mathrm{Li}_{3} \mathrm{PS}_{4}$ & Li-In & $5(2.5)$ & 150 & 100 & 837 & 1.68 & 13.8 & 48 \\
\hline
\end{tabular}

$\mathrm{Li}_{2} \mathrm{~S} / \mathrm{S}$ cells:

\begin{tabular}{|c|c|c|c|c|c|c|c|c|c|}
\hline Cathode & Electrolyte & Anode & $\begin{array}{c}\text { Weight of } \\
\text { cathode } \\
\text { (loading) } \\
\text { (mg) }\end{array}$ & $\begin{array}{c}\text { Weight } \\
\text { of SE } \\
\text { (mg) }\end{array}$ & $\begin{array}{c}\text { Weight } \\
\text { of } \\
\text { anode } \\
\text { (mg) }\end{array}$ & $\begin{array}{l}\text { Capacity } \\
\left(\mathrm{mAh} \mathrm{g}^{-1}\right)\end{array}$ & $\begin{array}{c}\text { Average } \\
\text { voltage } \\
\text { (V) }\end{array}$ & $\begin{array}{c}\text { Energy } \\
\text { density } \\
(\mathrm{Wh} \\
\left.\mathrm{kg}^{-1}\right)\end{array}$ & Ref. \\
\hline S & $\mathrm{Li}_{3} \mathrm{PS}_{4}$ & $\mathrm{Li}$ & $\begin{array}{c}0.796 \\
(0.285)\end{array}$ & 120 & 2 & 1200 & 2.28 & 6.4 & 49 \\
\hline $\mathrm{S}$ & $\mathrm{Li}_{3.25} \mathrm{Ge}_{0.25} \mathrm{P}_{0.75} \mathrm{~S}_{4}$ & $\mathrm{Li}-\mathrm{Al}$ & $5(0.45)$ & 70 & 45.2 & 1500 & 1.9 & 10.7 & 50 \\
\hline S & $77.5 \mathrm{Li}_{2} \mathrm{~S} \cdot 22.5 \mathrm{P}_{2} \mathrm{~S}_{5}$ & $\mathrm{Li}$ & $10(1.26)$ & 200 & 5 & 835 & 2.28 & 11.2 & 51 \\
\hline $\mathrm{S}$ & $\mathrm{Li}_{3.25} \mathrm{Ge}_{0.25} \mathrm{P}_{0.75} \mathrm{~S}_{4}$ & Li-In & $5(1.25)$ & 70 & 58.4 & 1200 & 1.68 & 18.9 & 52 \\
\hline $\mathrm{S}$ & $\mathrm{Li}_{3.25} \mathrm{Ge}_{0.25} \mathrm{P}_{0.75} \mathrm{~S}_{4}$ & $\mathrm{Li}-\mathrm{Al}$ & $5(1.25)$ & 70 & 25.2 & 900 & 1.9 & 21.3 & 53 \\
\hline $\mathrm{S}$ & $\mathrm{Li}_{3.25} \mathrm{Ge}_{0.25} \mathrm{P}_{0.75} \mathrm{~S}_{4}$ & $\mathrm{Li}-\mathrm{Al}$ & $5(2.5)$ & 70 & 25 & 559 & 1.9 & 26.6 & 54 \\
\hline $\mathrm{Li}_{2} \mathrm{~S}$ & $\mathrm{Li}_{3} \mathrm{PS}_{4}$ & Li-In & $\begin{array}{c}2.355 \\
(0.8835)\end{array}$ & 80 & 182 & 1100 & 1.68 & 6.2 & 55 \\
\hline $\mathrm{Li}_{2} \mathrm{~S}$ & $\mathrm{Li}_{3} \mathrm{PS}_{4}$ & In & $10(2.5)$ & 80 & 46 & 620 & 1.68 & 19.1 & 56 \\
\hline $\mathrm{Li}_{2} \mathrm{~S}$ & $80 \mathrm{Li}_{2} \mathrm{~S} \cdot 20 \mathrm{P}_{2} \mathrm{~S}_{5}$ & In & $10(2.5)$ & 80 & 57.4 & 800 & 1.68 & 22.8 & 57 \\
\hline $\mathrm{Li}_{2} \mathrm{~S}$ & $\mathrm{Li}_{6} \mathrm{PS}_{5} \mathrm{Cl}$ & In & $10(6)$ & 150 & 96.98 & 830 & 1.68 & 32.6 & 58 \\
\hline
\end{tabular}




\begin{tabular}{|l|l|c|c|c|c|c|c|c|c|}
\hline $\mathrm{Li}_{2} \mathrm{~S}$ & $\begin{array}{l}0.01 \mathrm{Li}_{3} \mathrm{PO}_{4} \cdot 0.63 \mathrm{~L} \\
\mathrm{i}_{2} \mathrm{~S} \cdot 0.36 \mathrm{SiS}_{2}\end{array}$ & In & $30(4.5)$ & 50 & 57.4 & 1170 & 1.68 & 64.4 & 59 \\
\hline $\mathrm{Li}_{2} \mathrm{~S}$ & $70 \mathrm{Li}_{2} \mathrm{~S} \cdot 30 \mathrm{P}_{2} \mathrm{~S}_{5}$ & Graphite & $25(4.4)$ & 50 & 40 & 750 & 2.28 & 65.4 & 60 \\
\hline $\mathrm{Li}_{2} \mathrm{~S}$ & $\mathrm{Li}_{7} \mathrm{P}_{3} \mathrm{~S}_{11}$ & Graphite & $40(5)$ & 50 & 25 & 750 & 2.28 & 74.3 & 61 \\
\hline $\mathrm{Li}_{2} \mathrm{~S}$ & $\mathrm{Li}_{3} \mathrm{PS}_{4}$ & $\mathrm{Li}$ & $16.3(6)$ & $\begin{array}{c}12 \\
(0.84)\end{array}$ & 1.88 & 912.4 & 2.1 & 370.6 & $\begin{array}{c}\text { this } \\
\text { work }\end{array}$ \\
\hline
\end{tabular}

\section{Supplementary References}

(1) Trevey, J. E.; Gilsdorf, J. R.; Miller, S. W.; Lee, S.-H. $\mathrm{Li}_{2} \mathrm{~S}-\mathrm{Li}_{2} \mathrm{O}-\mathrm{P}_{2} \mathrm{~S}_{5}$ Solid Electrolyte for All-Solid-State Lithium Batteries. Solid State Ionics 2012, 214, 25-30.

(2) Woo, J. H.; Trevey, J. E.; Cavanagh, A. S.; Choi, Y. S.; Kim, S. C.; George, S. M.; Oh, K. H.; Lee, S.-H. Nanoscale Interface Modification of $\mathrm{LiCoO}_{2}$ by $\mathrm{Al}_{2} \mathrm{O}_{3}$ Atomic Layer Deposition for Solid-State Li Batteries. J. Electrochem. Soc. 2012, 159 (7), A1120-A1124.

(3) Choi, S.; Kim, J.; Eom, M.; Meng, X.; Shin, D. Application of a Carbon Nanotube (CNT) Sheet as a Current Collector for All-Solid-State Lithium Batteries. J. Power Sources 2015, 299, 70-75.

(4) Kim, J.; Eom, M.; Noh, S.; Shin, D. Effect of Mixing Method on the Properties of Composite Cathodes for All-Solid-State Lithium Batteries Using $\mathrm{Li}_{2} \mathrm{~S}-\mathrm{P}_{2} \mathrm{~S}_{5}$ Solid Electrolytes. $J$. Power Sources 2013, 244, 476-481.

(5) Hakari, T.; Deguchi, M.; Mitsuhara, K.; Ohta, T.; Saito, K.; Orikasa, Y.; Uchimoto, Y.; Kowada, Y.; Hayashi, A.; Tatsumisago, M. Structural and Electronic-State Changes of a Sulfide Solid Electrolyte during the Li Deinsertion-Insertion Processes. Chem. Mater. 2017, 29 (11), 4768-4774. 
(6) Trevey, J. E.; Jung, Y. S.; Lee, S.-H. High Lithium Ion Conducting $\mathrm{Li}_{2} \mathrm{~S}-\mathrm{GeS}_{2}-\mathrm{P}_{2} \mathrm{~S}_{5}$ GlassCeramic Solid Electrolyte with Sulfur Additive for All-Solid-State Lithium Secondary Batteries. Electrochim. Acta 2011, 56 (11), 4243-4247.

(7) Noh, S.; Kim, J.; Eom, M.; Shin, D. Surface Modification of $\mathrm{LiCoO}_{2}$ with $\mathrm{Li}_{3 \mathrm{x}} \mathrm{La}_{2 / 3-\mathrm{x}} \mathrm{TiO}_{3}$ for All-Solid-State Lithium Ion Batteries Using $\mathrm{Li}_{2} \mathrm{~S}-\mathrm{P}_{2} \mathrm{~S}_{5}$ Glass-Ceramic. Ceram. Int. 2013, 39 (7), 8453-8458.

(8) Ohta, N.; Takada, K.; Zhang, L.; Ma, R.; Osada, M.; Sasaki, T. Enhancement of the HighRate Capability of Solid-State Lithium Batteries by Nanoscale Interfacial Modification. $A d v$. Mater. 2006, 18 (17), 2226-2229.

(9) Zhang, W.; Richter, F. H.; Culver, S. P.; Leichtweiss, T.; Lozano, J. G.; Dietrich, C.; Bruce, P. G.; Zeier, W. G.; Janek, J. Degradation Mechanisms at the $\mathrm{Li}_{10} \mathrm{GeP}_{2} \mathrm{~S}_{12} / \mathrm{LiCoO}_{2}$ Cathode Interface in an All-Solid-State Lithium-Ion Battery. ACS Appl. Mater. Interfaces 2018, 10 (26), 22226-22236.

(10)Ohta, N.; Takada, K.; Sakaguchi, I.; Zhang, L.; Ma, R.; Fukuda, K.; Osada, M.; Sasaki, T. $\mathrm{LiNbO}_{3}$-Coated $\mathrm{LiCoO}_{2}$ as Cathode Material for All-Solid-State Lithium Secondary Batteries. Electrochem. Commun. 2007, 9 (7), 1486-1490.

(11)Kitaura, H.; Hayashi, A.; Ohtomo, T.; Hama, S.; Tatsumisago, M. Fabrication of ElectrodeElectrolyte Interfaces in All-Solid-State Rechargeable Lithium Batteries by Using a Supercooled Liquid State of the Glassy Electrolytes. J. Mater. Chem. 2011, 21 (1), 118-124. 
(12)Teragawa, S.; Aso, K.; Tadanaga, K.; Hayashi, A.; Tatsumisago, M. Preparation of $\mathrm{Li}_{2} \mathrm{~S}-$ $\mathrm{P}_{2} \mathrm{~S}_{5}$ Solid Electrolyte from N-methylformamide Solution and Application for All-Solid-State Lithium Battery. J. Power Sources 2014, 248, 939-942.

(13)Li, W. J.; Hirayama, M.; Suzuki, K.; Kanno, R. Fabrication and Electrochemical Properties of a $\mathrm{LiCoO}_{2}$ and $\mathrm{Li}_{10} \mathrm{GeP}_{2} \mathrm{~S}_{12}$ Composite Electrode for Use in All-Solid-State Batteries. Solid State Ionics 2016, 285, 136-142.

(14)Noh, S.; Nichols, W. T.; Park, C.; Shin, D. Enhanced Energy Density and Electrochemical Performance of All-Solid-State Lithium Batteries Through Microstructural Distribution of Solid Electrolyte. Ceram. Int. 2017, 43 (17), 15952-15958.

(15)Noh, S.; Nichols, W. T.; Cho, M.; Shin, D. Importance of Mixing Protocol for Enhanced Performance of Composite Cathodes in All-Solid-State Batteries Using Sulfide Solid Electrolyte. J. Electroceram. 2018, 40 (4), 293-299.

(16)Zhang, W.; Leichtweiss, T.; Culver, S. P.; Koerver, R.; Das, D.; Weber, D. A.; Zeier, W. G.;

Janek, J. The Detrimental Effects of Carbon Additives in $\mathrm{Li}_{10} \mathrm{GeP}_{2} \mathrm{~S}_{12}$-Based Solid-State Batteries. ACS Appl. Mater. Interfaces 2017, 9 (41), 35888-35896.

(17)Choi, Y. E.; Park, K. H.; Kim, D. H.; Oh, D. Y.; Kwak, H. R.; Lee, Y. G.; Jung, Y. S. Coatable $\mathrm{Li}_{4} \mathrm{SnS}_{4}$ Solid Electrolytes Prepared from Aqueous Solutions for All-Solid-State Lithium-Ion Batteries. ChemSusChem 2017, 10 (12), 2605-2611.

(18)Zhang, W.; Weber, D. A.; Weigand, H.; Arlt, T.; Manke, I.; Schroder, D.; Koerver, R.; Leichtweiss, T.; Hartmann, P.; Zeier, W. G.; et al. Interfacial Processes and Influence of 
Composite Cathode Microstructure Controlling the Performance of All-Solid-State Lithium Batteries. ACS Appl. Mater. Interfaces 2017, 9 (21), 17835-17845.

(19)Eom, M.; Choi, S.; Son, S.; Choi, L.; Park, C.; Shin, D. Enhancement of Lithium Ion Conductivity by Doping $\mathrm{Li}_{3} \mathrm{BO}_{3}$ in $\mathrm{Li}_{2} \mathrm{~S}-\mathrm{P}_{2} \mathrm{~S}_{5}$ Glass-Ceramics Electrolytes for All-Solid-State Batteries. J. Power Sources 2016, 331, 26-31.

(20)Takahara, H.; Takeuchi, T.; Tabuchi, M.; Kageyama, H.; Kobayashi, Y.; Kurisu, Y.; Kondo, S.; Kanno, R. All-Solid-State Lithium Secondary Battery Using Oxysulfide Glass. $J$. Electrochem. Soc. 2004, 151 (10), A1539-A1544.

(21)Takada, K. Solid-State Lithium Battery with Graphite Anode. Solid State Ionics 2003, 158 (3-4), 269-274.

(22)Nam, Y. J.; Cho, S. J.; Oh, D. Y.; Lim, J. M.; Kim, S. Y.; Song, J. H.; Lee, Y. G.; Lee, S. Y.; Jung, Y. S. Bendable and Thin Sulfide Solid Electrolyte Film: A New Electrolyte Opportunity for Free-Standing and Stackable High-Energy All-Solid-State Lithium-Ion Batteries. Nano Lett. 2015, $15(5), 3317-3323$.

(23)Ohtomo, T.; Hayashi, A.; Tatsumisago, M.; Kawamoto, K. All-Solid-State Batteries With $\mathrm{Li}_{2} \mathrm{O}-\mathrm{Li}_{2} \mathrm{~S}-\mathrm{P}_{2} \mathrm{~S}_{5}$ Glass Electrolytes Synthesized by Two-Step Mechanical Milling. J. Solid State Electr. 2013, 17 (10), 2551-2557.

(24)Ohtomo, T.; Hayashi, A.; Tatsumisago, M.; Tsuchida, Y.; Hama, S.; Kawamoto, K. AllSolid-State Lithium Secondary Batteries Using the $75 \mathrm{Li}_{2} \mathrm{~S} \cdot 25 \mathrm{P}_{2} \mathrm{~S}_{5}$ Glass and the $70 \mathrm{Li}_{2} \mathrm{~S} \cdot 30 \mathrm{P}_{2} \mathrm{~S}_{5}$ Glass-Ceramic as Solid Electrolytes. J. Power Sources 2013, 233, 231-235. 
(25)Kato, Y.; Hori, S.; Saito, T.; Suzuki, K.; Hirayama, M.; Mitsui, A.; Yonemura, M.; Iba, H.;

Kanno, R. High-Power All-Solid-State Batteries Using Sulfide Superionic Conductors. Nat.

Energy 2016, 1 (4), 16030.

(26)Kato, Y.; Shiotani, S.; Morita, K.; Suzuki, K.; Hirayama, M.; Kanno, R. All-Solid-State

Batteries with Thick Electrode Configurations. J. Phys. Chem. Lett. 2018, 9 (3), 607-613.

(27)Kitaura, H.; Hayashi, A.; Tadanaga, K.; Tatsumisago, M. Electrochemical Performance of All-Solid-State Lithium Secondary Batteries with Li-Ni-Co-Mn Oxide Positive Electrodes.

Electrochim. Acta 2010, 55 (28), 8821-8828.

(28)Rosero-Navarro, N. C.; Kinoshita, T.; Miura, A.; Higuchi, M.; Tadanaga, K. Effect of The Binder Content on the Electrochemical Performance of Composite Cathode Using $\mathrm{Li}_{6} \mathrm{PS}_{5} \mathrm{Cl}$

Precursor Solution in an All-Solid-State Lithium Battery. Ionics 2017, 23 (6), 1619-1624.

(29)Chida, S.; Miura, A.; Rosero-Navarro, N. C.; Higuchi, M.; Phuc, N. H. H.; Muto, H.;

Matsuda, A.; Tadanaga, K. Liquid-Phase Synthesis of $\mathrm{Li}_{6} \mathrm{PS}_{5} \mathrm{Br}$ Using Ultrasonication and Application to Cathode Composite Electrodes in All-Solid-State Batteries. Ceram. Int. 2018, 44 (1), 742-746.

(30)Sakuda, A.; Takeuchi, T.; Kobayashi, H. Electrode Morphology in All-Solid-State Lithium Secondary Batteries Consisting of $\mathrm{LiNi}_{1 / 3} \mathrm{Co}_{1 / 3} \mathrm{Mn}_{1 / 3} \mathrm{O}_{2}$ and $\mathrm{Li}_{2} \mathrm{~S}-\mathrm{P}_{2} \mathrm{~S}_{5}$ Solid Electrolytes. Solid State Ionics 2016, 285, 112-117.

(31)Sakuda, A.; Kuratani, K.; Yamamoto, M.; Takahashi, M.; Takeuchi, T.; Kobayashi, H. AllSolid-State Battery Electrode Sheets Prepared by a Slurry Coating Process. J. Electrochem. Soc. 2017, 164 (12), A2474-A2478. 
(32)Koerver, R.; Aygün, I.; Leichtweiß, T.; Dietrich, C.; Zhang, W.; Binder, J. O.; Hartmann, P.;

Zeier, W. G.; Janek, J. Capacity Fade in Solid-State Batteries: Interphase Formation and

Chemomechanical Processes in Nickel-Rich Layered Oxide Cathodes and Lithium

Thiophosphate Solid Electrolytes. Chem. Mater. 2017, 29 (13), 5574-5582.

(33)Ito, S.; Fujiki, S.; Yamada, T.; Aihara, Y.; Park, Y.; Kim, T. Y.; Baek, S.-W.; Lee, J.-M.;

Doo, S.; Machida, N. A Rocking Chair Type All-Solid-State Lithium Ion Battery Adopting $\mathrm{Li}_{2} \mathrm{O}-\mathrm{ZrO}_{2}$ Coated $\mathrm{LiNi}_{0.8} \mathrm{Co}_{0.15} \mathrm{Al}_{0.05} \mathrm{O}_{2}$ and a Sulfide Based Electrolyte. J. Power Sources 2014, 248, 943-950.

(34)Nam, Y. J.; Oh, D. Y.; Jung, S. H.; Jung, Y. S. Toward Practical All-Solid-State Lithium-Ion Batteries with High Energy Density and Safety: Comparative Study for Electrodes Fabricated by Dry- and Slurry-Mixing Processes. J. Power Sources 2018, 375, 93-101.

(35)Mizuno, F.; Hayashi, A.; Tadanaga, K.; Minami, T.; Tatsumisago, M. All-Solid-State Lithium Secondary Batteries Using a Layer-Structured $\mathrm{LiNi}_{0.5} \mathrm{Mn}_{0.5} \mathrm{O}_{2}$ Cathode Material. $J$. Power Sources 2003, 124 (1), 170-173.

(36)Kitaura, H.; Hayashi, A.; Tadanaga, K.; Tatsumisago, M. All-Solid-State Lithium Secondary Batteries Using $\mathrm{LiMn}_{2} \mathrm{O}_{4}$ Electrode and $\mathrm{Li}_{2} \mathrm{~S}-\mathrm{P}_{2} \mathrm{~S}_{5}$ Solid Electrolyte. J. Electrochem. Soc. 2010, 157 (4), A407-A411.

(37)Kitaura, H.; Hayashi, A.; Tadanaga, K.; Tatsumisago, M. Improvement of Electrochemical Performance of All-Solid-State Lithium Secondary Batteries by Surface Modification of $\mathrm{LiMn}_{2} \mathrm{O}_{4}$ Positive Electrode. Solid State Ionics 2011, 192 (1), 304-307. 
(38)Xu, X.; Takada, K.; Watanabe, K.; Sakaguchi, I.; Akatsuka, K.; Hang, B. T.; Ohnishi, T.;

Sasaki, T. Self-Organized Core-Shell Structure for High-Power Electrode in Solid-State Lithium

Batteries. Chem. Mater. 2011, 23 (17), 3798-3804.

(39)Yao, X.; Liu, D.; Wang, C.; Long, P.; Peng, G.; Hu, Y. S.; Li, H.; Chen, L.; Xu, X. High-

Energy All-Solid-State Lithium Batteries with Ultralong Cycle Life. Nano Lett. 2016, 16 (11),

7148-7154.

(40)Kim, T. W.; Park, K. H.; Choi, Y. E.; Lee, J. Y.; Jung, Y. S. Aqueous-Solution Synthesis of $\mathrm{Na}_{3} \mathrm{SbS}_{4}$ Solid Electrolytes for All-Solid-State Na-Ion Batteries. J. Mater. Chem. A 2018, 6 (3), $840-844$.

(41)Shin, B. R.; Jung, Y. S. All-Solid-State Rechargeable Lithium Batteries Using $\mathrm{LiTi}_{2}\left(\mathrm{PS}_{4}\right)_{3}$

Cathode with $\mathrm{Li}_{2} \mathrm{~S}-\mathrm{P}_{2} \mathrm{~S}_{5}$ Solid Electrolyte. J. Electrochem. Soc. 2013, 161 (1), A154-A159.

(42)Yue, J.; Han, F.; Fan, X.; Zhu, X.; Ma, Z.; Yang, J.; Wang, C. High-Performance AllInorganic Solid-State Sodium-Sulfur Battery. ACS Nano 2017, 11 (5), 4885-4891.

(43)Fan, X.; Yue, J.; Han, F.; Chen, J.; Deng, T.; Zhou, X.; Hou, S.; Wang, C. HighPerformance All-Solid-State Na-S Battery Enabled by Casting-Annealing Technology. ACS Nano 2018, 12 (4), 3360-3368.

(44)Long, P.; Xu, Q.; Peng, G.; Yao, X.; Xu, X. NiS Nanorods as Cathode Materials for AllSolid-State Lithium Batteries with Excellent Rate Capability and Cycling Stability.

ChemElectroChem 2016, 3 (5), 764-769.

(45)Trevey, J. E.; Stoldt, C. R.; Lee, S.-H. High Power Nanocomposite TiS 2 Cathodes for AllSolid-State Lithium Batteries. J. Electrochem. Soc. 2011, 158 (12), A1282-A1289. 
(46)Oh, D. Y.; Choi, Y. E.; Kim, D. H.; Lee, Y.-G.; Kim, B.-S.; Park, J.; Sohn, H.; Jung, Y. S. All-Solid-State Lithium-Ion Batteries with $\mathrm{TiS}_{2}$ Nanosheets and Sulphide Solid Electrolytes. $J$. Mater. Chem. A 2016, 4 (26), 10329-10335.

(47)Shin, B. R.; Nam, Y. J.; Oh, D. Y.; Kim, D. H.; Kim, J. W.; Jung, Y. S. Comparative Study of $\mathrm{TiS}_{2} / \mathrm{Li}$-In All-Solid-State Lithium Batteries Using Glass-Ceramic $\mathrm{Li}_{3} \mathrm{PS}_{4}$ and $\mathrm{Li}_{10} \mathrm{GeP}_{2} \mathrm{~S}_{12}$ Solid Electrolytes. Electrochim. Acta 2014, 146, 395-402.

(48)Shin, B. R.; Nam, Y. J.; Kim, J. W.; Lee, Y. G.; Jung, Y. S. Interfacial Architecture for Extra $\mathrm{Li}^{+}$Storage in All-Solid-State Lithium Batteries. Sci. Rep. 2014, 4, 5572.

(49)Lin, Z.; Liu, Z.; Fu, W.; Dudney, N. J.; Liang, C. Lithium Polysulfidophosphates: A Family of Lithium-Conducting Sulfur-Rich Compounds for Lithium-Sulfur Batteries. Angew. Chem. Int. Ed. Engl. 2013, 52 (29), 7608-7611.

(50)Suzuki, K.; Tateishi, M.; Nagao, M.; Imade, Y.; Yokoi, T.; Hirayama, M.; Tatsumi, T.;

Kanno, R. Synthesis, Structure, and Electrochemical Properties of a Sulfur-Carbon Replica Composite Electrode for All-Solid-State Li-Sulfur Batteries. J. Electrochem. Soc. 2016, 164 (1), A6178-A6183.

(51)Trevey, J. E.; Gilsdorf, J. R.; Stoldt, C. R.; Lee, S.-H.; Liu, P. Electrochemical Investigation of All-Solid-State Lithium Batteries with a High Capacity Sulfur-Based Electrode. $J$.

Electrochem. Soc. 2012, 159 (7), A1019-A1022.

(52)Suzuki, K.; Kato, D.; Hara, K.; Yano, T.-a.; Hirayama, M.; Hara, M.; Kanno, R. Composite Sulfur Electrode Prepared by High-Temperature Mechanical Milling for use in an All-Solid- 
State Lithium-Sulfur Battery with a $\mathrm{Li}_{3.25} \mathrm{Ge}_{0.25} \mathrm{P}_{0.75} \mathrm{~S}_{4}$ Electrolyte. Electrochim. Acta 2017, 258, 110-115.

(53)Kobayashi, T.; Imade, Y.; Shishihara, D.; Homma, K.; Nagao, M.; Watanabe, R.; Yokoi, T.; Yamada, A.; Kanno, R.; Tatsumi, T. All-Solid-State Battery with Sulfur Electrode and ThioLISICON Electrolyte. J. Power Sources 2008, 182 (2), 621-625.

(54)Nagao, M.; Suzuki, K.; Imade, Y.; Tateishi, M.; Watanabe, R.; Yokoi, T.; Hirayama, M.;

Tatsumi, T.; Kanno, R. All-Solid-State Lithium-Sulfur Batteries with Three-Dimensional Mesoporous Electrode Structures. J. Power Sources 2016, 330, 120-126.

(55)Hakari, T.; Hayashi, A.; Tatsumisago, M. Li 2 S-Based Solid Solutions as Positive Electrodes with Full Utilization and Superlong Cycle Life in All-Solid-State Li/S Batteries. $A d v$.

Sustainable Syst. 2017, 1 (6), 1700017.

(56)Nagao, M.; Hayashi, A.; Tatsumisago, M.; Ichinose, T.; Ozaki, T.; Togawa, Y.; Mori, S. $\mathrm{Li}_{2} \mathrm{~S}$ Nanocomposites Underlying High-Capacity and Cycling Stability in All-Solid-State Lithium-Sulfur Batteries. J. Power Sources 2015, 274, 471-476.

(57)Nagao, M.; Hayashi, A.; Tatsumisago, M. High-Capacity Li 2 S-Nanocarbon Composite Electrode for All-Solid-State Rechargeable Lithium Batteries. J. Mater. Chem. A 2012, 22 (19), 10015-10020.

(58)Han, F.; Yue, J.; Fan, X.; Gao, T.; Luo, C.; Ma, Z.; Suo, L.; Wang, C. High-Performance All-Solid-State Lithium-Sulfur Battery Enabled by a Mixed-Conductive $\mathrm{Li}_{2} \mathrm{~S}$ Nanocomposite. Nano Lett. 2016, 16 (7), 4521-4527. 
(59)Takeuchi, T.; Kageyama, H.; Nakanishi, K.; Tabuchi, M.; Sakaebe, H.; Ohta, T.; Senoh, H.; Sakai, T.; Tatsumi, K. All-Solid-State Lithium Secondary Battery with $\mathrm{Li}_{2} \mathrm{~S}-\mathrm{C}$ Composite Positive Electrode Prepared by Spark-Plasma-Sintering Process. J. Electrochem. Soc. 2010, 157 (11), A1196-A1201.

(60)Takeuchi, T.; Kageyama, H.; Nakanishi, K.; Ohta, T.; Sakuda, A.; Sakaebe, H.; Kobayashi, H.; Tatsumi, K.; Ogumi, Z. Rapid Preparation of $\mathrm{Li}_{2} \mathrm{~S}-\mathrm{P}_{2} \mathrm{~S}_{5}$ Solid Electrolyte and Its Application for Graphite/Li 2 S All-Solid-State Lithium Secondary Battery. ECS Electrochem. Lett. 2014, 3 (5), A31-A35.

(61)Takeuchi, T.; Kageyama, H.; Nakanishi, K.; Ohta, T.; Sakuda, A.; Sakai, T.; Kobayashi, H.; Sakaebe, H.; Tatsumi, K.; Ogumi, Z. Application of Graphite-Solid Electrolyte Composite Anode in All-Solid-State Lithium Secondary Battery with $\mathrm{Li}_{2} \mathrm{~S}$ Positive Electrode. Solid State Ionics 2014, 262, 138-142. 